\title{
Effectiveness of Continuous Glucose Monitoring in Children, Adolescents and Young Adults with Poorly Controlled Type 1 Diabetes
}

\author{
Kevin R. Lewis \\ West Virginia University
}

Follow this and additional works at: https://researchrepository.wvu.edu/etd

\section{Recommended Citation \\ Lewis, Kevin R., "Effectiveness of Continuous Glucose Monitoring in Children, Adolescents and Young Adults with Poorly Controlled Type 1 Diabetes" (2013). Graduate Theses, Dissertations, and Problem Reports. 546.}

https://researchrepository.wvu.edu/etd/546

This Dissertation is protected by copyright and/or related rights. It has been brought to you by the The Research Repository @ WVU with permission from the rights-holder(s). You are free to use this Dissertation in any way that is permitted by the copyright and related rights legislation that applies to your use. For other uses you must obtain permission from the rights-holder(s) directly, unless additional rights are indicated by a Creative Commons license in the record and/ or on the work itself. This Dissertation has been accepted for inclusion in WVU Graduate Theses, Dissertations, and Problem Reports collection by an authorized administrator of The Research Repository @ WVU.

For more information, please contact researchrepository@mail.wvu.edu. 
Effectiveness of Continuous Glucose Monitoring in Children, Adolescents and Young Adults with Poorly Controlled Type 1 Diabetes

\author{
Kevin R. Lewis \\ Doctoral Capstone Project submitted to the School of Nursing \\ at West Virginia University \\ In partial fulfillment of the requirements for the \\ Doctor of Nursing Practice Degree
}

Susan McCrone, $\mathrm{PhD}$, Chair

Pam Deiriggi, $\mathrm{PhD}$

Sachin Bendre, MD, PhD

Morgantown, West Virginia

2013

Keywords: continuous glucose monitoring, diabetes, children, adolescents \& uncontrolled Subject Category: Nursing 0569

Copyright 2013 Kevin R. Lewis 


\begin{abstract}
Effectiveness of Continuous Glucose Monitoring in Children, Adolescents and Young Adults with Poorly Controlled Type 1 Diabetes
\end{abstract}

Kevin R. Lewis

\title{
Background
}

Type 1 diabetes is the second most common chronic illness seen in children. Children, adolescents and young adults with type 1 diabetes are provided care in programs with diabetes educators, nurses, nurse practitioners, physicians, dietitians, and many other specialists. Even though children, adolescents and young adults receive care from many providers, their diabetes is often not in good control. In the last 10 years a new device called a continuous glucose monitor has been developed for use with people with diabetes. This new device documents the blood sugar levels in people with diabetes between finger stick blood sugar tests.

\section{Objectives}

This study utilized a newly developed investigational continuous glucose monitoring device in children, adolescents and young adults ages 7-21 who had very high blood sugars and a hemoglobin A1c of $9 \%$ or greater. The rationale was that if the participants could see their blood sugars in between regular testing, it would help them to lower their blood sugars. The study used the Family Approach to Diabetes Management model to improve adherence to wearing the CGM monitor. The primary outcome of the study was to improve HbAlc by at least $0.5 \%$. Secondary outcomes of the study included: adherence to wearing the continuous glucose monitor, adherence to blood sugar testing, decrease in hypoglycemia, and change in quality of life indicators.

\section{Design}

This study used a prospective, one group, pre and post-test pre experimental design with a convenience sample of patients. The 12-week intervention tested the efficacy of a newly developed continuous glucose monitor on glycemic control. Participants were seen every four weeks during the study. At the baseline visit, demographic data were collected and participants completed the Quality of Life for Youth form. Patients and families were taught to use the continuous glucose monitor, and the basic concepts of the Family Approach to Diabetes Management Model. Baseline HgAlc levels were determined as well as reported and actual frequency of blood testing was determined. Data collected at the subsequent visits included downloads from of the continuous glucose monitor, home finger stick blood glucose monitor and completion of a qualitative interview about experiences with the monitor use. In addition, data collected at the final study visit included collection of HbAlcs and completion of the Quality of Life for Youth forms. 


\section{Subjects}

Thirty-three subjects enrolled in the study. Twenty-one (63.6\%) completed the final study visit at 12 weeks. The mean age of the subjects was 15.57 years with a range of 11 to 20 years. Of the 21 that finished the study, $47.6 \%$ were male and $52.4 \%$ were female.

Results

There was a clinically and statistically significant improvement in HbA1c from baseline by $1.1095 \%(\mathrm{SD}=1.9321) p=0.016$. Fifteen of the participants $(71.4 \%)$ had an improvement of greater than $0.5 \%$ in HbA1c. Participants wore the CGM monitor a mean of 51.1429 (SD $=20.68543$ ) days with a range of 21 to 81 days. For this study, wearing the monitor any part of the day was counted as one day. The participants wore the monitor a mean of 4.262 days a week. At the end of the study, two participants were identified as manipulating the CGM device and did not provide accurate finger stick blood glucoses to calibrate the monitor. The change in $\mathrm{HbA} 1 \mathrm{c}$ was recalculated removing these participants from the analysis resulting in, a mean improvement of $1.4579 \%(\mathrm{SD}=1.6711) p=0.001$. While there were no significant differences in quality of life among the six subscales evaluated, there was a trend in improvement of areas of symptoms, treatment, parental issues, worry, and health. Data derived from qualitative interviews demonstrated an improved attitude among the participants and improved parent child interaction.

Conclusion

Continuous glucose monitoring with the Family Approach to Diabetes Management model was effective in improving glycemic control with children, adolescents and young adults with poorly controlled diabetes. 


\section{Acknowledgements}

I would like to thank all of the people that gave me support and encouragement over the years to further my education and make this project work.

- To my committee members, Dr. Susan McCrone, Dr. Pamela Deiriggi, and Dr. Sachin Bendre I thank you for all of your support during extended timeline to finish this project. To Dr. McCrone, I thank you especially for all of the many countless hours that you put into helping me make this project succeed.

- To Dr. Stacey Culp for your statistical support and guidance.

- $\quad$ To my colleagues, especially Dr. Amanda Dye for her support.

- To our clinic nurses and staff for all of their work and assistance in with the study visits.

- To the WVU Department of Pediatrics, Charleston Division for their support and allowing me to complete this project.

- To Medtronic Minimed for their generous grant of continuous glucose monitors and sensors for my study. Without their grant, this study would not have happened.

- To Charleston Area Medical Center Research and Grants Administration for their financial grant to make this project a success.

- To my partner Adam Viski, I thank you for all of your support, love and persistence that I would finish this project. I thank you for not getting discouraged with me over the many hours of being ignored while I stared at a computer screen for numerous evenings over the last several years of my program. I thank you for all of our road trips where you said you would drive so I could work on schoolwork.

- To my parents Gerald and Gloria Lewis, I thank you for instilling in my head the value of an education at a very young age. 
Table of Contents

$\begin{array}{ll}\text { Abstract } & 2\end{array}$

$\begin{array}{ll}\text { Acknowledgements } & 4\end{array}$

$\begin{array}{ll}\text { Table of Contents } & 5\end{array}$

$\begin{array}{ll}\text { Table of Tables } & 7\end{array}$

$\begin{array}{ll}\text { Table of Appendix } & 7\end{array}$

CHAPTER 1 INTRODUCTION

$\begin{array}{ll}\text { Background and Significance } & 8\end{array}$

$\begin{array}{ll}\text { Theoretical Framework } & 10\end{array}$

Application of Theory 11

$\begin{array}{ll}\text { Problem Statement } & 14\end{array}$

CHAPTER II REVIEW OF THE LITERATURE

$\begin{array}{ll}\text { Search Strategy } & 16\end{array}$

$\begin{array}{ll}\text { Clinical Appraisal } & 17\end{array}$

$\begin{array}{ll}\text { Synthesis } & 20\end{array}$

$\begin{array}{ll}\text { Discussion } & 21\end{array}$

$\begin{array}{ll}\text { Conclusion } & 22\end{array}$

$\begin{array}{ll}\text { Project Objectives } & 22\end{array}$

$\begin{array}{ll}\text { Stakeholders } & 24\end{array}$

Congruence of Organizational Strategic Plan to the Capstone Project 24

CHAPTER III METHODOLOGY

Evidence Base Project $\quad 26$

$\begin{array}{ll}\text { Procedures/Protocol } & 27\end{array}$ 
Timeline of Project $\quad 30$

$\begin{array}{ll}\text { Resources } & 32\end{array}$

Financial Plan/Budget $\quad 33$

CHAPTER IV RESULTS

$\begin{array}{ll}\text { Evaluation } & 34\end{array}$

$\begin{array}{ll}\text { Demographics } & 34\end{array}$

$\begin{array}{ll}\text { Glycemic control } & 37\end{array}$

$\begin{array}{ll}\text { Adherence } & 38\end{array}$

$\begin{array}{ll}\text { Hypoglycemia } & 39\end{array}$

$\begin{array}{ll}\text { Quality of life questionnaires } & 40\end{array}$

$\begin{array}{ll}\text { Qualitative questionnaire findings } & 40\end{array}$

CHAPTER V SUMMARY, DISCUSSION, IMPLICATIONS

$\begin{array}{ll}\text { Congruence with Theoretical Model } & 43\end{array}$

$\begin{array}{ll}\text { Discussion } & 44\end{array}$

$\begin{array}{ll}\text { Recommendations } & 48\end{array}$

$\begin{array}{ll}\text { Conclusion } & 48\end{array}$

$\begin{array}{ll}\text { REFERENCES } & 50\end{array}$ 
Table of Tables and Appendices

$\begin{array}{ll}\text { Table 1. Capstone Timeline } & 29\end{array}$

Table 2. Gender $\quad 35$

Table 3. Race 35

Table 4. Other Health Conditions Reported 35

Table 5. Insulin Delivery Method 36

Table 6. Primary Caregiver 35

Table 7. Family Description 35

Table 8. Baseline Demographics for Participants that Completed the Study 37

Appendix A Evidence of Key Site Support $\quad 52$

Appendix B Continuous Glucose Monitoring Data Collection Tool 53

Appendix C Qualitative Tool $\quad 55$

Appendix D Capstone Budget $\quad 56$

Appendix E Agreement for use of Quality of Life Tool 59 
Effectiveness of Continuous Glucose Monitoring in Children, Adolescents and Young Adults with Poorly Controlled Type 1 Diabetes

\section{CHAPTER 1 INTRODUCTION}

\section{Background and Significance}

\section{Background}

Type 1 diabetes is the second most common chronic childhood illness, and it is estimated that there are 215,000 children under the age of 20 with type 1 diabetes in the United States (Centers for Disease Control and Prevention, 2011). Type 1 diabetes is a manageable lifelong chronic disease, and if well controlled, a person can live a long and productive life. Unfortunately, in spite of aggressive diabetes management strategies, a large majority of children, adolescents and young adults with diabetes are not adequately controlled (Silverstein et al., 2005). Poorly controlled diabetes can lead to a number of chronic complications which can ultimately lead to blindness, kidney failure, nerve damage, and heart disease (Sperling, 2002). Continuous glucose monitoring (CGM) has been shown to improve glycemic control in children, adolescents and young adults when worn 6 or more days per week (Juvenile Diabetes Research Foundation Continuous Glucose Monitoring Study Group, 2009). This study will evaluate the effectiveness of CGM in children, adolescents and young adults with poorly controlled diabetes in improving glycemic control, adherence to the diabetes treatment regimen, and quality of life. The study tested a new investigational sensor that can be worn for up to six days a week. 


\section{Significance}

Adolescents are in a time of transition from relying on parents for total care to complete self-care as an adult. Teenage rebellion can complicate the adolescent's ability to be successful at completing all of the tasks associated with the diabetes management regimen. In the past, adolescents who did not adhere to adequate self-care behaviors have classically been labeled as non-compliant or difficult to manage.

If optimal care and adherence is not achieved, the patient is at higher risk for developing both acute and chronic complications of diabetes (Schilling, Knafl, \& Grey, 2006). Acute complications of diabetes can include diabetic keto-acidosis (DKA) and hypoglycemia. While DKA has a high rate of resolution, approximately 1 in 100 children with DKA will have a poor outcome including death or permanent disability (Sperling, 2002). Severe hypoglycemia can also have potentially grave outcomes (Sperling, 2002). Chronic complications of poorly controlled diabetes can include: retinopathy, neuropathy, nephropathy, heart disease, and hypertension (Sperling, 2002). While long-term complications may take many years to develop, once present, they are irreversible and all have permanent lifelong consequences (Sperling, 2002). The goals for glycemic control in the population is an HbA1c level $<8 \%$ (Silverstein et al., 2005).

Several factors can be associated with increasing difficulty in managing adolescent diabetes. Puberty can cause a significant increase in insulin requirements (Sperling, 2002). Widely varying schedules can necessitate the need for flexible insulin regimens to achieve glycemic control. Teenage rebellion can complicate an adolescent's ability to be successful at completing all of the tasks associated with the diabetes management regimen. Because the needs 
of children, adolescents and young adults with type 1 diabetes are complex, their self-care is best facilitated by a multidisciplinary team that can address all of the health and psychosocial needs of children, adolescents and young adults (Sperling, 2002).

\section{Theoretical Framework}

\section{Identification of Clinical Problem}

Children, adolescents and young adults with type 1 diabetes present unique challenges that complicate the normal growth and development seen at this age. Diabetes management including blood sugar testing, insulin injections, and dietary restrictions complicate the daily activities of these groups. As children grow into adolescents and young adults, these challenges continue to be more difficult (Schilling et al., 2006). While a number of educational theories exist to address delivery of diabetes education to patients, none address the complexities of dealing with children, adolescents and young adults with diabetes and their families as a whole. The Family Approach to Diabetes Management was developed from a family therapy model specifically designed to address the patient and the family as a whole (Solowiejczyk, 2004).

\section{Explanation of the Model}

The Family Approach to Diabetes Management (FADM) model directly addresses the problem of poor adherence to diabetes self-care and the family's integral effect on self-care behaviors (Solowiejczyk, 2004). Tenets of the model are that diabetes is a complex disease affecting the whole family, that no other chronic disease places so many burdens on the child, adolescent and young adult, and that family function has a direct role on outcomes of metabolic control. The FADM model was developed based on the unpublished findings of work done at Children's Hospital of Philadelphia (CHOP) in the 70's and 80's using a family therapy 
approach to chronic care. The author of the model, Solowiejczyk, was a member of the original study group. The staff at CHOP utilized their findings to develop a model that could be applied to children, adolescents and young adults with diabetes. Unfortunately, these initial findings were not published, but Solowiejczyk utilized these earlier findings to develop this model. A major factor was identified that led to a higher likelihood of positive outcomes was that positive family communication is essential to create behavior patterns that will lead to successful selfcare. Other major determinants of a positive outcome were the mother's sense of how supported she felt and the ease of getting the family scheduled for education sessions (Solowiejczyk, 2004).

Clinical assumptions of the model are based on the following factors: the family's resources, needs and rules affecting the outcomes for the child, and expectations of self-care. The patient is the entire family and must be treated as a whole unit. Responsibility for self-care is not an option, it is the expected behavior (Solowiejczyk, 2004). Parents are the rule makers in the home; they control the money, food, clothes, car, and recreational activities. Because they control all of these factors, they need to set expectations for self-care, and also to determine the consequences for poor self-care behavior. Mismanagement of diabetes should be treated the same as not doing chores or homework, i.e., you don't have to like it; you just have to do it. The main thought is children will rise to the highest level they are asked to achieve.

\section{Theory Application}

The populations for the capstone project were children, adolescents and young adults ages 7-21 with poorly controlled diabetes (HbA1c level at $9 \%$ or higher). The intervention utilizes continuous glucose monitoring to increase awareness of blood sugar patterns so that the patient and family could have a greater understanding of the implications of the diabetes self- 
management behaviors. In addition to providing a greater understanding of how the person's behaviors affects his or her diabetes self-care, the CGM device gives instant feedback in the form of a real time trend of the individual's blood sugar values. The family can use these values to look back at the individual's day and evaluate how well he or she did in managing the diabetes that day. The patient and family can utilize the findings to make adjustments to the insulin regimen utilizing pattern management to adjust the insulin doses to improve the glycemic control.

Diabetes affects the family as a whole. In a large majority of cases where the child/adolescent/young adult is in poor glycemic control, the patient and parent interactions focus on negative feedback from the parent and are often seen as nagging. For example, if the individual has a high blood sugar, the parent and their child/adolescent/young adult may be in a disagreement because the blood sugar is elevated instead of utilizing this moment as a learning point for the dyad. For example, if the patient did not take his or her insulin, the parent can put a plan in place to help make sure someone helps him or her get the proper dose of insulin at the right time. If the blood sugar is elevated because the patient did not calculate the proper dose of insulin, the parent can review each of the foods that the patient commonly eats and generate or devise a quick list of common foods and amount of insulin based on each usual serving he or she eats. The goal of the model is to refocus the family to positive communication patterns, to set reasonable and attainable goals for self-care measures, and to have a plan for consequences of undesirable behaviors.

Past studies have shown that benefit from use of CGM monitors is only obtained when the monitor is worn at least $70 \%$ of the time (Wilson et al., 2011). Because the intervention is dependent upon the use of the device to be successful, the family was asked to meet together on 
a regular interval to discuss the diabetes care behaviors and come up with a plan based on how the family perceives the patient is doing based on blood sugar patterns. Initially, the family was asked to meet each evening for 5-10 minutes to review the blood sugars on the CGM device. The family would then reflect on the pattern of blood sugars and identify problems with particular foods or missed insulin doses. The treatment team asked the family to meet daily until both the patient and parent agreed that the individual was doing well with insulin dosing and calculating insulin doses based on food consumption. If the patient was having trouble with dosing of insulin or testing the blood sugar and calibrating the sensor, the team would give them strategies to improve this behavior, such as the family sitting together each time the patient tested the blood sugar, determining the insulin dose together, and supervising or giving the insulin dose.

Once they were meeting the basics of diabetes care, the family could space these meetings out to every three days. The meetings every three days were used to reinforce self-care activities and to review the blood sugars to adjust the insulin doses based on these patterns. Once the family was meeting the goals of blood sugar control and self-care activities, they were able to space the family meetings out to once a week. The purpose of this meeting was to review the self-care measures and glycemic control. If the parent found that the patient was not doing well, the family meetings needed to be moved back to every three days or even daily.

In the event that the child/adolescent did not meet the basics of self-care even with daily meetings, the parent needed to be willing to implement consequences for poor behaviors. These consequences needed to be age specific and individually tailored. For example, consequences for older adolescents that wanted to learn to drive or be able to drive their parent's car could be the loss of driving privileges for a predetermined amount of time. For younger adolescents it could be tied to money, use of cell phones, computer use or other luxuries that would have a 
negative impact on the adolescent and improve the self-care behaviors. The consequence were time-limited and appropriate, for example, loss of cell phone use for one week If the behavior improved, the patient could get the privilege back the next week. If not, he or she would lose it for another week. The primary purpose for the use of the model was not only to improve family communications, but also to improve diabetes self-care behaviors and ultimately increase the use of continuous glucose monitoring.

\section{Importance/Relevance to Nursing Practice}

Healthcare of children, adolescents and young adults with type 1 diabetes has significant implications for nursing practice. Care is best provided by a multidisciplinary team that includes diabetes nurse educators and nurse practitioners. If optimal care and adherence is not achieved, the patient is at higher risk for developing both short and long term complications of diabetes (Schilling et al., 2006). The Family Approach to Diabetes Management (FADM) model is directly applicable to the study population and the goals of increasing adherence to tasks associated with diabetes self-management (Solowiejczyk, 2004). This model was developed by the Solowiejczyk, utilizing the originally developed concepts from earlier studies that were unpublished (Solowiejczyk, 2004).

\section{Summary}

The FADM model was designed to treat diabetes in children as a family problem and not just a disease of the child. The model provides a framework to promote family communication with the ultimate goal of increasing adherence to diabetes self-care tasks. A major problem identified in children, adolescents and young adults with type 1 diabetes is poor adherence to their diabetes care. This model was used to promote the use of the CGM monitor during the 
study. The families were taught at visit one to have regular family meetings based on blood sugar goals for the patient. They also developed consequences that the patient and family agreed to put into place for unacceptable behaviors related to diabetes care. The family was encouraged to track the use of the model by entering the family meetings into the patient diary. 


\section{CHAPTER II REVIEW OF THE LITERATURE}

\section{Project Description}

\section{Introduction and Background}

In the past 10 years, continuous glucose monitoring has been developed with the goal of improving the outcomes in people with diabetes (Blevins et al., 2010). The standard of diabetes care includes traditional diabetes education intervention and management in a multidisciplinary setting (Sperling, 2002). Some data are available on the efficacy of continuous glucose monitoring on improving outcomes of diabetes care. Studies have been conducted to evaluate the efficacy of CGM in children, adolescents, and adults with diabetes (Blevins et al., 2010). However, a gap exists in the literature as to whether CGM improved HbA1c in children, adolescents and young adults with poorly controlled diabetes. The review of the literature herein focused on the following question: In children, adolescents and young adults ages 7-21 with poorly controlled type 1 diabetes (HbAlc at 9\% or higher) does continuous glucose monitoring

improve glycemic control as evidenced by $\mathrm{HbA1c}$, adherence to diabetes self-care behaviors, and quality of life.

\section{Search Strategy}

A comprehensive search strategy was developed to locate the best evidence for effectiveness of continuous glucose monitoring use in children, adolescents and young adults with poorly controlled type 1 diabetes. and its effect on lowering HbAlc. The search included a search of: National Guideline Clearinghouse, The Cochrane Library, Academic Search Complete, PubMed, and CINAHL. These databases were searched using the key words: continuous glucose monitoring, diabetes, children, and adolescents. There was no limit on 
geographic location, but studies were limited to the last eight years. The search was limited to English language and to subjects less than 18 years of age. The initial search that included all of the key terms returned 45 articles. Further searches were completed using combinations of key words including continuous glucose monitoring and diabetes, which returned 437 papers. No clinical practice guidelines specifically for use of CGM in children or adolescents were found, however an adult guideline with a small pediatric section was identified. The search was limited to articles that were systematic reviews, randomized controlled trials, non-randomized controlled trials, and cohort studies that were published from 2005 to 2013 . Snowballing was utilized to find further studies, but none were found. The titles of the 437 papers that were found were manually scanned for applicability to the search. Finally, seven studies were included in the review, two systematic reviews, and six randomized controlled studies. These studies were included because they had pediatric subjects who utilized the continuous glucose monitor and had outcomes relevant to this project.

\section{Critical Appraisal}

A critical appraisal of each of the eight articles was completed utilizing appropriate appraisal tools. The systematic reviews were appraised utilizing the Scottish Intercollegiate Guideline Network form for systematic reviews. The six randomized control trials were appraised utilizing the SIGN (2012) form for randomized control trials. The first systematic review evaluated outcomes of glycemic control in children, adolescents, and adults from six studies (Joubert \& Reznik, 2011). All of the six studies focused on the use of insulin pump therapy with CGM monitoring and showed improved outcomes of glycemic control compared to standard and multiple injection therapy. Secondary findings of most of the studies showed improvement in $\mathrm{HbA} 1 \mathrm{c}$ for participants that wore the device more than $70 \%$ of the time. This 
review is limited in application to this study because the focus is on concurrent use of CGM and Continuous Subcutaneous Insulin Infusion (CSII) in adolescents.

The other systematic review evaluated a total of 14 studies (Wojciechowski, Ryś, Lipowska, Gawęska, \& Małecki, 2011). Eight of these studies were based on current CGM systems (worn continuously), which gives the patient instant information. Six studies were based on older retrospective systems for diagnostic intermittent use. The studies that evaluated the current continuous CGM system showed an HbA1c improvement ranging from $0.15-0.43 \%$, the average improvement in this group was $0.27 \%$, with the lowering of both groups' HbA1c by 0.26\% ( $p<0.0001)$ (Wojciechowski, Ryś, Lipowska, Gawęska, \& Małecki, 2011). The authors found inconsistencies in ways that hypoglycemia and hyperglycemia were reported making secondary analysis of the data difficult. Due to the variety of ways in which the studies reported the ages, the authors were not able to report findings in the 8 to 18 year age range. These studies showed favorable findings for use of CGM when compared to standard finger stick blood sugar testing alone.

Two of the RCT studies (Battelino et al., 2011; Raccah et al., 2009) evaluated the use of CGM in conjunction with insulin pump therapy also known as continuous subcutaneous insulin infusion (CSII). Both studies evaluated children, adolescents and adults. Each study lasted one year and evaluated HbAlcs. They both compared a group using continuous subcutaneous insulin infusion with CGM technology to a control group of patients on injection therapy that were not using CGM. In each of these studies, the CGM group showed improvement in HbA1c by $0.51 \%$ $(p<0.001)$ and $0.27 \%(p=0.008)$, respectively over the group on injection therapy that did not use the CGM monitor. 
The Juvenile Diabetes Research Foundation (JDRF) CGM study group evaluated 322 adults and children with HbA1c levels ranging from $7-10 \%$ in a RCT utilizing CGM (Tamborlane et al., 2008). They found that adults had a significant lowering in HbA1c levels. Children ages 8-14 had less hypoglycemia (even though the study was not designed to measure hypoglycemia significance), but did not have an improvement in HbAlc levels $(p=0.29)$. Adults ( $>$ age 25) that had improvement in HbA1c levels utilized the CGM device six or more days per week, those ages 15 to 24 utilized the device $30 \%$ of the time and children ages 8 to 14 , $50 \%$ of the time. Strength of the study was that a large number of adults were evaluated during the study. The small number of children in the study limited the study, and there was no secondary analysis of subsets of the population done to evaluate outcomes based on the amount of time that the device was used.

The Juvenile Diabetes Research Foundation (JDRF) CGM study group in another study evaluated 129 participants ages 8 to 69 years with $\mathrm{HbA} 1 \mathrm{c}<7.0 \%$; they compared a treatment group that utilized a CGM monitor to a control group that did standard finger stick blood sugar testing alone (Beck et al., 2009b). The investigators evaluated the outcomes at six months for each of the groups. The participants had less time at hypoglycemia compared to the control group, but the difference was not statistically significant $(p=0.43)$. The investigators found reduction in $\mathrm{HbA} 1 \mathrm{c}$, a difference of improvement of $0.34 \%$ compared to the control group, without worsening of hypoglycemia $(p<0.001)$. Strengths of the study included the large study population and comparable control group. The weakness of the study was that only patients that were very well controlled were sampled, and there was no stratification of HbAlc by ages.

The remaining two RCT studies evaluated the use of CGM in patients with type 1 diabetes that were well-controlled (Battelino et al., 2011; Beck et al., 2009a). The first study 
evaluated 120 adults and children and showed that both children and adults had improvement of HbA1c of $0.27 \%(p<0.001)$ and less hypoglycemia with use of CGM when compared to the control group $(p<0.001)$. The second study also showed that participants had less time spent in hypoglycemia compared to the control $(\mathrm{p}=0.009)$ and improved HbAlc levels $>/=0.3 \%$ $(p=<0.001)$ with CGM use. This study showed improvement in HbAlc when the device was worn 6 or more days a week. Strengths of the studies included the duration of 26 weeks, and they were designed to evaluate hypoglycemia and HbAlc improvement. A weakness of the studies was the difficulty in evaluating outcomes specifically in children based on how the patients' ages were stratified in the data analysis.

\section{Synthesis}

All of the studies reviewed evaluated children with diabetes and CGM use. Two systematic reviews and 5 RCTs showed improvement in HbA1c levels with CGM use in children and adolescents. Two RCTs (Battelino et al., 2011; Beck et al., 2009b) showed decreases in hypoglycemia with CGM use while improving HbA1c levels. One of the studies (Tamborlane et al., 2008) showed no significant improvement in HbA1c levels. None of the studies evaluated the use of CGM in patients with HbA1c $>10 \%$. These studies show the benefits of CGM in children, adolescents, and adults who wore the device 6 days a week or more (Beck et al., 2009a).

One of the systematic reviews found a higher percentage of patients reaching a goal of HbA1c with an intervention of continuous glucose monitoring (CGM) and a secondary effect of less hypoglycemia (Wojciechowski et al., 2011). The second systematic review found a lowering of HbA1c of 0.5 to1.0\% without increased risk of hypoglycemia (Joubert \& Reznik, 2011). Each of the systematic reviews included studies with both adults and children. One RCT 
evaluated factors affecting improved outcome of HbAlc, and found that improved HbAlc was seen in patients that wore the sensor $>70 \%$ of the time (Joubert \& Reznik, 2011)). One RCT showed benefit of CGM in adults that wore CGM, but did not show the same results in children and adolescents due to their wearing the device less often (Tamborlane et al., 2008). Two of the RCT studies evaluated the outcome of hypoglycemia in groups, both adults and children, that were at or close to HbA1c goal and showed less hypoglycemia (Battelino et al., 2011; Beck et al., 2009b). Two RCTs showed improvement in HbA1c when utilizing CGM with concurrent initiation of insulin pump therapy (Battelino et al., 2011; Raccah et al., 2009).

\section{Discussion}

The literature review identified the need for further research to evaluate the effectiveness of CGM on adherence to treatment, and improving HbA1c in children, adolescents and young adults with diabetes, especially those with poor diabetes control. Quality of life is another variable that needs to be addressed that was not considered in the studies. All but one of the studies utilizing CGM (Tamborlane et al., 2008) showed statistically significant improvement in HbA1c levels, but pediatric participants in this study did not wear the CGM on an almost daily basis. One study found improvement in $\mathrm{HbA} 1 \mathrm{c}$ in this population when the CGM was worn 6 or more days a week (Beck et al., 2009a). The proposed study evaluated the short-term use (12 weeks) of CGM in children, adolescents and young adults with HbA1c levels of 9\% or higher. The potential benefits of this intervention in improving HbAlc levels are important for this population. While this intervention has been found to improve HbA1c levels in children, adolescents and young adults who are at goal of HbA1c or near goal, this was the first study undertaken in children, adolescents and young adults with very high $\mathrm{HbA} 1 \mathrm{c}$ levels. 


\section{Conclusion}

Children, adolescents and young adults with diabetes present unique challenges that are not seen in adults. In addition to everyday challenges of diabetes self-management, normal issues observed in growth and development can complicate the self-care regimen. While standard diabetes education has been shown to improve HbAlc levels in general, HbAlc levels in at-risk populations have continued to rise in spite of standard diabetes education. Improvement of metabolic control in diabetes is important in decreasing the risk of potential complications including: retinopathy, nephropathy, neuropathy, and heart disease. HbA1c improvement has been shown to significantly decrease the risk of these complications.

A systematic review of the literature has shown that continuous glucose monitoring is effective in lowering HbA1c levels. Further studies need to be completed to verify the effectiveness of this intervention in lowering HbA1c levels in children, adolescents and young adults with very high HbA1c levels. Due to the higher costs associated with CGM, long term studies need to be done to show the benefits, especially in high-risk populations benefit. While there are no long-term studies to evaluate the decrease in chronic complication of diabetes, shortterm improvement may suggest a decrease in long-term risk of complications. Such studies could show benefit to this at-risk population and justify that insurance companies cover this therapy as standard of care.

\section{Project Objectives}

The first objective was to improve HbA1c levels in children, adolescents and young adults with poorly controlled diabetes by using continuous glucose monitoring. 
This study was done at WVU Pediatric Endocrinology clinic in Charleston, WV. The goal was to recruit 40 patients ages 7-21 with an HbA1c level of 9\% or higher. HgAlc was measured at baseline and again at a 3-month visit to evaluate the change in HbA1c. The research plan included strategies to help the family and participant meet the goals of wearing the continuous glucose monitor 6 or more days a week. The goal was to improve HbA1c, thereby decreasing risk of long-term risk of complications. A lowering of $\mathrm{HbAlc}$ level by $0.5 \%$ is considered to be clinically significant.

The second objective was to increase adherence to the diabetes regimen by using continuous glucose monitoring. The team measured adherence to the diabetes regimen at baseline and at one, two and three months to evaluate the outcome. The team utilized the Family Approach to Diabetes management model to improve the patient's likelihood of adhering to finger stick glucose monitoring. This approach needed to be employed to increase the likelihood that the participant would adhere to testing the blood sugar three or more times a day. The research plan included strategies to help the family and participant meet the goals of increasing blood sugar testing (adherence). The goal was to improve testing to three or more times a day.

The third objective was to improve quality of life in children, adolescents and young adults with poorly controlled diabetes by using continuous glucose monitoring.

The team measured Quality of Life utilizing the Quality of Life Short form at baseline and at three months. The Family Approach to Diabetes management model was used to improve the patient's likelihood of adhering to the use of the continuous glucose monitor. This approach needed to be employed to increase the likelihood that the participant would use the device 6 or more days a week, which was shown to improve outcomes in previous studies. The evaluation 
of quality of life was a secondary objective of the study. The research plan included strategies to help the family and participant meet the goals of wearing the continuous glucose monitor 6 or more days a week. The goal was that it would improve the quality of life for participants.

The fourth objective was to help the participants deal with the increased pain associated with use of the CGM sensor, finger stick blood sugar testing, and insulin injections.

The goal was to increase the participant's adherence to the treatment regimen by increasing blood sugar testing, insulin injections and use of the CGM six or more days a week. The team gave the patient tips for decreasing pain associated with use of diabetes related tasks in the form of a handout to identify resources available. Participants were given lidocaine / prilocaine cream at time of entry into the study to be used for pain associated with insertion of the CGM sensor. The goal was for participants to have increased blood sugar testing, increased self-reporting of insulin injections and use of CGM device 6 or more days a week by download at the one month follow up.

\section{Congruence of Organizations Strategic Plan to Project}

Children, adolescents and young adults with diabetes are seen for regular follow up every three months in the pediatric endocrine clinic. Patients that have HbAlc levels at $10 \%$ or greater are seen at a more frequent interval of every 4 to 6 weeks. Several years ago, the organization held a high-risk clinic for children with elevated HbA1c levels. The program included diabetes educators, a dietitian, and a psychologist. The program only lasted one year. The patient show rate for the clinic was very low and after the year, the clinic could not be continued. The WVU pediatric endocrine practice currently follows 600 children with diabetes, with a large majority of these children being adolescents and young adults. In the practice, a significant number of these 
adolescents have $\mathrm{HbA} 1 \mathrm{c}$ levels greater than $8 \%$ and a number are greater than $10 \%$. The practice has approximately 130 children, adolescents and young adults with $\mathrm{HbA} 1 \mathrm{c}$ level at $9 \%$ or greater. The clinic is located in the Department of Pediatrics in the WVU School of Medicine, Charleston Division. The organizations mission includes patient care, research and service. The organization is supportive of the project and will allow adequate time and resources to make the project successful (Appendix A). 


\section{CHAPTER III METHODOLOGY}

\section{Project Design}

\section{Evidence Based Project/Intervention Plan}

This practice change project used a prospective, one group, pre and post-test pre experimental design, with a convenience sample of patients (Polit, D. F., 2008). Because this is a practice change, there was no control group. The practice change intended to place 40 participants on CGM for three months to compare the primary outcome of $\mathrm{HbAlc}$ at baseline and at 3 months. In addition, quality of life utilizing the Diabetes Quality of Life in Youth Short Form (Skinner, Hoey, McGee, \& Skovlund, 2006) was to be measured at both time points. The use of the Family Approach to Diabetes Management model was evaluated at each visit by reviewing the diary of visits. In addition to these measurements, other indicators of adherence including number of blood glucose tests per day and total amount of insulin taken daily (selfreported) was measured. The demographic data included age, gender, length of time since diagnosis of type 1 diabetes, family support system, family dynamics, and who was the primary caregiver (see Appendix B).

\section{Sample}

A convenience sample of 33 participants was recruited from the WVU Pediatric Endocrinology Clinic in Charleston WV. Participants were ages 9-20 years with type 1 diabetes and $\mathrm{HbA} 1 \mathrm{c} 9 \%$ or greater. Twenty-one of the participants completed the study. Parents of patients under 18 signed a consent form and patients an assent form. Patients over 18 signed a consent form.

To increase the likelihood of participants would return for follow up study visits, the study offered an incentive program for each study visit completed. The incentive was $\$ 20$ for 
the baseline visit and for each of the follow-up visits. These incentives were in the form of WalMart gift cards. This was to help offset the costs of travel to participate in the study.

\section{Procedures/Protocol}

Participants who met inclusion criteria completed consent/assent forms and a baseline HbA1c was drawn. Data for the number of blood sugar tests done daily were obtained from blood glucose meter downloads, and the total amount of self -reported insulin taken during the day was recorded. The Quality of Life in Diabetes Youth Short Form was administered. Participants were then instructed on the use of the Medtronic Guardian CGM device and Enlite sensor. The Guardian CGM system is an FDA approved device that is to be used as an adjunct to regular blood sugar testing. The Enlite sensor is a minimally invasive sensor that works with the Guardian device to determine the patient's blood sugar. The device is investigational and does not currently have FDA approval for sale in the US, although the device is approved for use in 35 other countries. The device does not pose a significant risk to the patient, is minimally invasive and is used only as a trending device to make insulin adjustments. The patient needed to test his or her blood sugar at least twice a day to calibrate the system in order to get a reading on the sensor. The patients were instructed to test their blood sugars to determine the accurate dosing of insulin and any time the CGM monitor identified that they had a low blood sugar $(<$ $70 \mathrm{mg} / \mathrm{dL})$. The device was initiated in the office. Follow up visits occurred at 1 and 2 months after enrollment. At each follow up visit, the investigators downloaded the meter, CGM device, and made insulin adjustments as needed. Participants then received supplies for the next 4 weeks. The final study visit was at the 3 months. At the final study visit, the investigators obtained HbA1c levels, downloaded the blood glucose meter to determine frequency of blood sugar tests, obtained self-reported insulin dosing, and re-administered the Quality of Life in 
Diabetes Youth Short Form. The diary tracking family meetings utilizing the FAMD model were reviewed at each study visit. After the study was completed, the patients were given their CGM system, and the investigators attempted to obtain insurance authorization for sensors for continued use of the device.

Risks

The primary goal of the intervention was to lower HbA1c levels, but lowering HbA1c carries with it the risk of an increase of hypoglycemic events. The increased risk is associated with improved control and not the actual use of the CGM monitor. Because previous studies have shown less likelihood of hypoglycemia with the use of the CGM device, the potential risks of implementing CGM were considered to be minimal.

\section{Primary Outcomes}

The primary study variables were the change in HbA1c levels. Secondary outcomes included adherence to treatment regimen, and quality of life measures. HbAlc levels were determined by point of care testing (POCT) in the clinic. The HbAlc level was drawn at baseline and at three months with a goal of at least $0.5 \%$ improvement in control as being clinically significant. The HbA1c levels were done using the Siemens DCA Vantage POCT system. This system has previously been evaluated and determined to meet the guidelines for glyco-hemoglobin standardization (Battelino et al., 2011). HgA1c data were analyzed using a paired t-test. Adherence to treatment regimen was evaluated by using data downloaded from the participants home blood glucose monitor and from the CGM monitor. These data were analyzed using a repeated measures ANOVA test. 
The study evaluated adherence to finger-stick blood sugar testing by recording the number of blood glucose tests done each day based on the 30-day average from the home meter download. CGM adherence was evaluated by recording the number of hours the patient wore the device from the CGM monitor data. These data were collected at monthly follow up visits and analyzed using a repeated measures ANOVA test.

The CGM downloads were evaluated by the number of hypoglycemic events recorded. The number of these events in the patient diary was then compared to the patient diary to evaluate the number of hypoglycemic events, duration of hypoglycemic events, and the number of hypoglycemic events that required assistance to treat.

Quality of life was measured utilizing the Quality of Life in Diabetes Youth Short Form (Skinner et al., 2006). A previous study of 2,077 young people found this tool to be both valid and reliable (Skinner et al., 2006). This is a 22-item form that was developed from an original 55 question Diabetes Quality of Life Youth Form; the old form was lengthy and redundant. This new form can be completed by the participants in about 5 minutes. The researchers found a statistically significant correlation between the new form and the older lengthy form in all areas except impact on activities. The subscales for form include impact of symptoms related to diabetes, impact of treatment, impact of activities, parent issues, worries about diabetes, and health perception. The answers are scored on a likert scale of $0-4$ with a higher number meaning worse quality of life in that area. The health perception is scored from 1-4 with a higher number being worse. This form was administered at the initial and three-month final study visit. The Novo Nordisk study group holds the copyright for this form. There was no charge to use the form for the study and data use agreement was in place and approved. A paired t-test was used to 
analyze the quality of life data. The Family Approach to Diabetes Management model was evaluated by diaries the patients completed for review at each at study visit.

\section{Conclusion}

Continuous glucose monitoring has the potential to add a valuable tool to treat what has traditionally been described as a difficult group of patients. In spite of comprehensive diabetes education and treatment, $\mathrm{HbA} 1 \mathrm{c}$ levels continue to rise in this group, and other interventions in the past have shown little improvement (Silverstein et al., 2005). This study evaluated the primary outcome of glycemic control. It also evaluated secondary outcomes including: adherence, quality of life and qualitative outcomes.

\section{Timeline of Project Phases}

\section{Clinical Initiatives Utilizing the Logic Model}

The logic model was revisited and utilized to develop the clinical initiatives, see Table 1 . The clinical initiatives were developed for use in the study to evaluate the effectiveness of continuous glucose monitoring for children, adolescents and young adults ages 7 to 21 with poorly controlled diabetes (HbA1c of $9 \%$ or greater).

Table 1

Project Timeline

\begin{tabular}{llll}
\hline Item to Be Addressed & \multicolumn{1}{c}{ Specific Plan } & \multicolumn{1}{c}{ Timeline } & Comments \\
\hline Obtain grant funding & Applied for grant & Grant was secured by & Late change in \\
for CGM monitor and & funding from & both agencies in & protocol required \\
supplies & Medtronic diabetes & December 2012 & additional time with \\
& and CAMC research & & IRB to approve the \\
& & use of an \\
\hline
\end{tabular}




\begin{tabular}{|c|c|c|c|}
\hline & institute. & & $\begin{array}{l}\text { investigational device. } \\
\text { Final grant was } \\
\text { received from CAMC } \\
\text { Research Institute to } \\
\text { cover study costs and } \\
\text { patient incentives. }\end{array}$ \\
\hline $\begin{array}{l}\text { Obtain permission for } \\
\text { use of Quality of Life } \\
\text { in Diabetes Youth } \\
\text { Short Form }\end{array}$ & $\begin{array}{l}\text { Email confirming use } \\
\text { of the form after } \\
\text { completing of use } \\
\text { agreement. }\end{array}$ & Completed & $\begin{array}{l}\text { Emailed copyright } \\
\text { holder to clarify that } \\
\text { the correct version } \\
\text { was in the agreement. }\end{array}$ \\
\hline $\begin{array}{l}\text { Develop education } \\
\text { plan for FADM model } \\
\text { for staff }\end{array}$ & $\begin{array}{l}\text { Using the FADM } \\
\text { model, we will } \\
\text { educate the nursing } \\
\text { staff on how to use } \\
\text { the model to educate } \\
\text { the families when } \\
\text { teaching them the } \\
\text { CGM device }\end{array}$ & $\begin{array}{l}\text { The nursing staff was } \\
\text { trained in using the } \\
\text { FADM model during } \\
\text { the study. }\end{array}$ & $\begin{array}{l}\text { Needed to educate the } \\
\text { staff on how to } \\
\text { educate the family to } \\
\text { buy into the model for } \\
\text { success. }\end{array}$ \\
\hline $\begin{array}{l}\text { Develop capstone } \\
\text { plan to present to } \\
\text { committee }\end{array}$ & $\begin{array}{l}\text { Plan developed by the } \\
\text { end of Nursing } 793\end{array}$ & $\begin{array}{l}\text { Plan completed by } \\
5 / 15 / 2012\end{array}$ & \\
\hline $\begin{array}{l}\text { Present capstone plan } \\
\text { to DNP Capstone } \\
\text { committee }\end{array}$ & $\begin{array}{l}\text { Present plan to } \\
\text { committee chair and } \\
\text { members for approval }\end{array}$ & $\begin{array}{l}\text { Plan was presented by } \\
7 / 15 / 2012\end{array}$ & \\
\hline Submission to IRB & $\begin{array}{l}\text { WVU IRB in was the } \\
\text { primary Morgantown } \\
\text { IRB, with secondary } \\
\text { approval needed from } \\
\text { Charleston IRB }\end{array}$ & November 30, 2012 & $\begin{array}{l}\text { There was delay } \\
\text { related to the use of } \\
\text { an investigational } \\
\text { device and the } \\
\text { requirement to get } \\
\text { approval through two } \\
\text { IRB's. }\end{array}$ \\
\hline $\begin{array}{l}\text { Recruit subjects to the } \\
\text { study, and complete } \\
\text { first visit (two groups } \\
\text { of } 20 \text { for three } \\
\text { months) }\end{array}$ & $\begin{array}{l}\text { Patient were } \\
\text { identified from POCT } \\
\text { labs done in office }\end{array}$ & $1 / 1 / 2013$ to $7 / 30 / 2013$ & \\
\hline $\begin{array}{l}\text { Participants seen at } \\
\text { follow up visits }\end{array}$ & $\begin{array}{l}\text { Participants seen at } 1 \\
\text { and } 2 \text { month follow } \\
\text { up visits where CGM } \\
\text { and blood glucose }\end{array}$ & $2 / 1 / 2013$ to $9 / 30 / 2013$ & \\
\hline
\end{tabular}




\begin{tabular}{lll}
\hline & $\begin{array}{l}\text { testing data was } \\
\text { obtained. }\end{array}$ & \\
Final visit for study & $\begin{array}{l}\text { Final data collection } \\
\text { obtained for all } \\
\text { participants }\end{array}$ & By $9 / 30 / 2013$ \\
Data analysis & $\begin{array}{l}\text { Data analysis } \\
\text { completed with } \\
\text { capstone chair, } \\
\text { completed }\end{array}$ & By $10 / 15 / 2013$ \\
& and statistician input \\
Presentation of & Final presentation \\
capstone to committee & \\
\hline
\end{tabular}

\section{Resources - Personnel, Technology, Budget}

\section{Costs Associated with the Study}

There were a number of direct and indirect costs associated with this study. The Medtronic Guardian continuous glucose monitors and Enlite sensor was provided by a grant from Medtronic. Other costs associated with the study included HbAlc levels done at baseline and 3 months for all 21 participants. Nursing time for each participant to teach the CGM device was estimated at 1.5 hours for each participant starting into the study. The investigators time and medical assistant's time to download the monitors were donated by the Department of Pediatrics and were not calculated into the costs of the study. The study also provided lidocaine / prilocaine cream free of charge for each of the participants to decrease the pain associated with the insertion of the CGM sensor. The study also budgeted a nominal amount for the investigator to travel to a meeting to disseminate the research findings. (Appendix D) 


\section{Sources of Study Funding}

The majority of the funding for indirect costs for the study was provided in the form of grant for study supplies from Medtronic. Medtronic Diabetes approved a grant for the Guardian Continuous Glucose Monitoring System, Enlite CGM sensors and sensor inserters for 21 of the participants. The funding to cover HbAlc levels, patient visit incentive and incidentals came from the Charleston Area Medical Center Research Fund. 


\section{CHAPTER IV RESULTS}

\section{Introduction}

The goal of this study was to evaluate the effectiveness of continuous glucose monitoring (CGM) in children, adolescents and young adults ages 7 to 21 years with poorly controlled type 1 diabetes (HbA1c level at 9\% or greater). The primary outcomes that were measured included glycemic control (HbA1c), adherence to the treatment regimen, hypoglycemia and quality of life.

\section{Demographics}

The total number of participants recruited into the study who completed the baseline study visit was 33. A total of 21 participants completed the final study visit. Demographics for the population were described in Table 2-8. The study had an attrition rate of $36.4 \%$. The reasons for attrition were as follows: one was not able to complete the visits due to family illness, two reported skin irritation from the adhesive tape on the glucose sensor, and the other nine did not continue because they did not wish to continue wearing the monitor. Some of participants did not like physically wearing the sensor, while others did not like the alarms from high blood glucose readings. The mean $\mathrm{HbAlc}$ of all participants at baseline was $10.515 \%$ $(\mathrm{SD}=1.4127)$ with a range of $9-14 \%$. The mean age of all participants was 15.42 years $(\mathrm{SD}=2.750)$ with a range of $9-20$ years. There was no difference in age $(p=0.691)$, duration of diabetes $(p=0.698), \mathrm{HbA1c}(p=0.655)$ or weight $(p=0.351)$ between the group that started the study and those that completed the study. Of the 21 that finished the study, $47.6 \%$ were male and $52.4 \%$ were female, 95.2\% were Caucasian and 4.8\% were African American. The ages of the group that finished the study ranged from 11 to 20 years of age with the mean being 15.57 $(\mathrm{SD}=2.657)$. Household demographics showed $57.1 \%$ of the subjects lived in a two parent 
household, $14.3 \%$ lived with their mother only, $9.5 \%$ lived with their father, $4.8 \%$ lived with grandparents, and the remaining $9.5 \%$ either lived by themselves or with a significant other.

Quality of life questionnaires were completed by $100 \%$ of the participants who completed the final study visit.

Demographics

Table 2

Gender

\begin{tabular}{lrr}
\hline & Frequency & Percent \\
\hline Male & 10 & 47.6 \\
Female & 11 & 52.4 \\
Total & 21 & 100.0 \\
\hline
\end{tabular}

Table 3

Race

\begin{tabular}{lrr}
\hline & Frequency & Percent \\
\hline Caucasian & 20 & 95.2 \\
African American & 1 & 4.8 \\
Total & 21 & 100.0 \\
\hline
\end{tabular}

Table 4

Other Reported Health Conditions

\begin{tabular}{lrr}
\hline & Frequency & Percent \\
\hline None & 14 & 66.7 \\
Addison disease & 1 & 4.8 \\
Celiac, hypothyroid & 1 & 4.8 \\
Depression & 1 & 4.8 \\
Hypertension & 1 & 4.8 \\
\hline
\end{tabular}




\begin{tabular}{lrr}
\hline Hypothyroid, Cholestero & 1 & 4.8 \\
Hypothyroid, HTN & 1 & 4.8 \\
Microalbuminuria & 1 & 4.8 \\
Total & 21 & 100.0 \\
\hline
\end{tabular}

Table 5

Insulin Delivery Method

\begin{tabular}{lrr}
\hline & Frequency & Per \\
\hline Injections & 9 & 42.9 \\
Pump & 12 & 57.1 \\
Total & 21 & 100.0 \\
\hline
\end{tabular}

Table 6

Primary Caregiver

\begin{tabular}{lrr}
\hline & Frequency & Percent \\
\hline Mother & 15 & 71.4 \\
Father & 2 & \\
Grandparent & 1 & 4.8 \\
Extended family & 1 & 4.8 \\
Other & 2 & 9.5 \\
Total & 21 & 100.0 \\
\hline
\end{tabular}

Table 7

\section{Family Description}

\begin{tabular}{lrr}
\hline Lives with & Frequency & Percent \\
\hline Mother & 3 & 14.3 \\
Father & 2 & 9.5 \\
Both parents & 12 & 57.1 \\
Grandparent & 1 & 4.8 \\
Other & 3 & 14.3 \\
Total & 21 & 100.0 \\
\hline
\end{tabular}


Table 8

\section{Baseline Descriptive Statistics Of Subjects that Completed Study}

\begin{tabular}{llrrrr}
\hline & N & Minimum & Maximum & Mean & Std. Deviation \\
\hline Age & 21 & 11 & 20 & 15.57 & 2.657 \\
Age at Diagnosis & 21 & 2 & 17 & 7.86 & 3.890 \\
Years With Diabetes & 21 & 1 & 17 & 7.74 & 4.200 \\
HBA1c & 21 & 9.0 & 14.0 & 10.600 & 1.4900 \\
BG daily test reported & 21 & 2.0 & 9.0 & 4.214 & 1.7859 \\
BG test from meter & 21 & .0 & 6.6 & 2.686 & 1.8610 \\
Insulin TDD & 21 & .56 & 1.75 & 1.0431 & .28858 \\
Total & 21 & & & & \\
\hline
\end{tabular}

\section{Glycemic control}

The mean baseline HbA1c of the participants completing the study was $10.600 \%$ $(\mathrm{SD}=1.49)$ with a range of $9-14 \%$. The mean HbA1c at completion of the study was $9.490 \%$ $(\mathrm{SD}=1.47)$ with a range of $7.3-12.3 \%$. This was a statistically significant HgbA1c improvement of $1.1095 \%(\mathrm{SD}=1.9321) p=0.016$. The change in HbA1c ranged from an improvement of $6.7 \%$ to worsening of $2.5 \%$.

\section{Significance of improvement}

Seventeen of the 21 participants demonstrated an improvement in HbAlc. The improvement in glycemic control ranged from $0.1 \%$ to $6.7 \%$. Two of the participants had improvements of less than $0.5 \%$. Fifteen of the participants had clinically significant improvement in $\mathrm{HbA} 1 \mathrm{c}>0.5 \%$. Eleven of the participants had an improvement between 0.5 and $2 \%$. Four of the participants had an improvement of greater than $2 \%$. The mean weight in the group increased by $1.4134 \mathrm{~kg}(\mathrm{SD}=2.7263) p=0.026$. 


\section{Participants without improvement}

Of the four participants who had a worsening HbAlc, two of these participants admitted to manipulation of the CGM device. One of the participants admitted at the final visit to entering false lower blood glucose values in the CGM to get the monitor to read lower blood glucose readings. The other participant admitted to not testing blood glucose values and entering fictitious readings into the monitor to keep the CGM reading. The HbAlc levels were recalculated removing these two subjects and a statistically significant reduction in mean HgbA1c remained. After exclusion of these subjects the mean baseline HbA1c was 10.668\% $(\mathrm{SD}=1.5532)$ and improved at final visit to $9.211 \%(\mathrm{SD}=1.2490)$. The mean improvement of HbA1c was therefore $1.4579 \%(\mathrm{SD}=1.6711) p=0.001$.

\section{Adherence}

Adherence was tracked at each visit and at the final visit. Home blood glucose meters were downloaded at each visit and participants also self-reported the number of times per day they were testing blood glucose values. Participants self-reported testing their blood sugars $4.214(\mathrm{SD}=1.7859)$ times a day at baseline with a range of 2-9 times per day. This increased to $4.3095(\mathrm{SD}=2.01542)$ at visit two and up to $4.342(\mathrm{SD}=2.3336)$ at visit 3 and slightly down to $4.071(\mathrm{SD}=2.4763)$ at the final visit. Therefore, a significant difference in self-reported glucose testing was not demonstrated. Blood glucose monitors were downloaded at each visit and the baseline mean number of actual tests per day was $2.686(\mathrm{SD}=1.8610)$ with a range of 0 to 6.6 . The mean increased to $3.781(\mathrm{SD}=2.5459)$ times per day at visit two, then declined to 3.284 $(\mathrm{SD}=2.2877)$ at visit three and down to $2.738(\mathrm{SD}=2.6447)$ at the final visit. There was no significant difference in number of blood glucose tests reported by the participants $(p=0.745)$ or 
actual ( $p=0.121)$ blood glucose values that were downloaded from the participant's blood glucose meter at each visit. When comparing reported number with actual blood glucose testing, there was significant difference in the number of tests reported versus actual at the baseline visit $(p=0.000)$, visit three $(p=0.017)$ and the final visit $(p=0.006)$. There was no difference between the number reported and actual download at visit $2(p=0.137)$.

Participants wore the CGM monitor for a mean of 51.14 days $(\mathrm{SD}=20.865)$ with a range of 20 to 81 days. The mean number of total hours the CGM was worn by participants was $820.4286(\mathrm{SD}=437.58423)$ with a range of 386 to 1674 hours. The mean sensor reading for the study was $211.05 \mathrm{mg} / \mathrm{dL}(\mathrm{SD}=34.683)$. There was no correlation between duration of sensor use and HbA1c improvement $(p=0.822)$. There was no difference in reported total daily dose of insulin given at each of the visits $(p=0.944)$. Participants were given a diary to complete for family meetings, significant hypoglycemia, and reasons for not wearing the CGM monitor. Only two out of the 21 diaries were returned so analysis of the diary data was not possible. None of the participants required/requested topical lidocaine / prilocaine cream for ease of CGM sensor insertion.

\section{Hypoglycemia}

Hypoglycemia was monitored by self-report at follow up visits and by analysis of CGM data download. One participant reported having a clinically significant hypoglycemic episode that required assistance to correct. This participant had two episodes within one week; the episodes were described as "passing out". Hypoglycemia was treated successfully with oral glucose and the participant did not require hospital emergency treatment. When reviewing the episodes with the participant, they both occurred when the participant was not wearing the continuous glucose monitor. The percentage of time the CGM area under the curve $<70 \mathrm{mg} / \mathrm{dL}$ 
was $0.500 \%(\mathrm{SD}=0.5030)$ with a range from 0 to $1.9 \%$. None of the time spent in hypoglycemia episodes reported by the CGM monitor require assistance to correct.

\section{Quality of life}

All participants that completed the final study visit completed all questions in the Quality of Life in Diabetes Youth Short Form questionnaire. The questionnaire includes six subsets that impacted diabetes. A higher number in each area is associated with worsening impact. The baseline mean of symptoms was $4.24(\mathrm{SD}=0.497)$ and improved to $3.67(\mathrm{SD}=0.532)$ at the final visit $p=0.319$. The baseline mean for treatment was $3.05(\mathrm{SD}=2.062)$ and improved to 2.43 $(\mathrm{SD}=2.378)$ at the final visit $p=0.242$. The baseline mean for activities was $2.76(\mathrm{SD}=3.419)$ and worsened to $3.76(\mathrm{SD}=4.657)$ at the final visit $p=0.144$. The baseline mean for parental impact was $6.48(\mathrm{SD}=3.459)$ and improved to $5.62(\mathrm{SD}=4.153)$ at the final visit $p=0.204$. The baseline mean for worry was $8.29(\mathrm{SD}=6.908)$ and improved to $7.10(\mathrm{SD}=7.063)$ at the final visit $p=0.258$. The baseline mean for health was $2.71(\mathrm{SD}=0.845)$ and improved to $2.48(\mathrm{SD}=0.814)$ at the final visit $p=0.204$. There was significant correlation for all items except for symptoms. There were no statistically significant improvements in quality of life in the six areas measured by the questionnaire although improvement was seen in all categories except activities.

Significance may not have been realized because of the small number of subjects or short duration of the intervention.

\section{Qualitative questionnaire findings}

Qualitative Data Analysis:

Qualitative data were collected at each of the follow up visits. Participants were asked if they met on a regular basis to review and discuss the use of the continuous glucose monitor. Thirteen $(61.9 \%)$ of the participants responded that they met on a regular basis. Four $(19.0 \%)$ 
reported that regular meetings did not occur. Four $(19.0 \%)$ of the participants lived on their own and did not have parental involvement in order to be able meet for the family meeting.

Of the thirteen participants who met on a regular basis to discuss glycemic control, selfreported topics of discussion revealed three major themes. The first theme identified was identification of blood sugar problems that were previously not recognized. Some of the findings reported included: higher blood glucose values at night which were not known, hyperglycemia before lunch and dinner, nocturnal hypoglycemia, post-prandial hyperglycemia and rebound hyperglycemia. The second common theme was seeing the CGM monitor catch hyperglycemia and hypoglycemia before they occurred. Participants were able to identify causes of glycemic deviation and the reasons the blood glucoses were going low or high at different times. The final common theme was the monitor helped keep them on track. This included noticing how different things affected blood glucose values. Other issues that were discussed included: family reviewing blood sugars, noting that the participant needed to test more frequently, and frequent sensor alarms. The families were instructed to determine consequences for participants that did not wear the CGM monitor on a regular basis. Eleven of the families reported that their child was wearing the device on a regular basis and did not require implementation of consequences. Two of the participants did not wear the CGM monitor on a regular basis, but the families did not implement consequences as directed. Four of the participants were living independently and did not have parental involvement to implement consequences. Two of the participants wore the monitor the majority of the time, but the parent did not review the monitor as was discussed in the treatment plan. These were the two participants that had manipulated the CGM to provide readings and because of this manipulation, they were not getting accurate readings. 
Participants were asked how the CGM monitor helped them at each follow up visit. Four themes were identified during the follow up visits. The first theme was improved attitude toward diabetes. Parents described the following areas that were related to behavior: improved attitude overall, changed attitude toward diabetes, making diabetes more tolerable, and improved interest in other activities. The child parent relationship was described as improved based on the following descriptions: added security when the child is away from the parent, parental piece of mind at night, decreased parental nagging, and improved mother/daughter relationships. The participants state that they feel better while wearing the CGM. They described this with the following: feels better now that blood sugar is better, knowing what blood sugar is all of the time, insulin is given more frequently because of increased awareness, it demonstrates how different foods affect the blood sugar, it helps understand how the blood sugar affects the way she feels, and they are watching things closer. The participants and parents also felt that the alarms were helpful to prevent low blood sugars with the predictive alarm, and to treat higher blood sugars quicker so they don't stay as high for as long. 


\section{CHAPTER V SUMMARY, DISCUSSION, IMPLICATIONS}

\section{Congruence with Theoretical Framework}

The Family Approach to Diabetes Management is a behavior modification program developed to bring families together to encourage children with diabetes to complete the basics of self-care to improve their self-management skills. This project uses basic concepts of the framework to involve the family in encouraging the participant to wear the CGM monitor. Past studies have shown improvement in HbA1c when the CGM sensor is worn for 6 or more days a week. All participants and families were trained in the basics of FAMD model at the study initiation visit and encouraged to utilize the concepts they had been taught at each follow up visits. Eleven of the families reported meeting on a regular basis and encouraged the participant to wear the sensor on a regular basis. Four of the participants were living on their own and were encouraged to have their close support system stress for them to wear the CGM monitor. Two of the participants wore the monitor on a consistent basis, however they manipulated the CGM data by entering in erroneous blood sugars that caused the monitor to provide false data. This shows that family involvement is essential to keep the adolescent on track and using the monitor correctly.

The FADM model can be successfully implemented into an outpatient clinic environment to help improve the outcomes of adolescents with diabetes. The model can be used to help encourage regular use of the CGM monitor. With proper presentation and integration into clinical practice, the FADM model can be seen by the child, adolescent or young adult not as a punishment, but as an encouragement and expectation to strive to improve their self-care behaviors. The parents in this study either fully supported the use of the CGM and reported the 
patient wore the monitor all of the time, or the patients were left to monitor their own self-care.

The parents that were not active in their patient's care during the study reported they were going to use the model after their last study visit to improve the self-care deficits that were identified in the study.

\section{Discussion}

\section{HbA1c}

There was a clinically and statistically significant improvement in HbA1c of $1.1095 \%$ $(\mathrm{SD}=1.9321) p=0.016$ during the 12 week study. At the end of the study, two participants were identified as manipulating the CGM device and did not provide accurate finger stick blood glucoses to calibrate the monitor. The change in HbA1c was recalculated after removing these 2 participants from the analysis and there was outliers a mean improvement of $1.4579 \%$ $(\mathrm{SD}=1.6711) p=0.001$. The studies that were identified from the literature search had HbA1c levels that ranged from no improvement to an improvement of 1\% (Battelino et al., 2011; Raccah et al., 2009; Joubert \& Reznik, 2011; Wojciechowski, Ryś, Lipowska, Gawęska, \& Małecki, 2011). For this study an improvement of $0.5 \%$ was considered clinically significant. Fifteen of the participants (71.4\%) had an improvement of greater than $0.5 \%$ in HbAlc. Eleven of the participants had final HbA1c levels that improved to less than 9\%. Two of those participants had final $\mathrm{HbA} 1 \mathrm{c}$ levels in the $7 \%$ range. A HbAlc of less than $8 \%$ is considered in goal for this age group (Silverstein et al., 2005). While not all participants had improvement in HbA1c, those that had clinically significant improvement in glycemic control ranged from $0.8 \%$ to $6.7 \%$. While the mean improvement of HbA1c was greater than the other studies that were reviewed, the baseline HbAlc was higher in this study, and therefore had more potential to improve. With 
intensification of glycemic control, there is risk of weight gain. The participants had a mean weight gain of $1.4134 \mathrm{~kg}(\mathrm{SD}=2.7263) p=0.026$, while the weight gain is statistically significant, it is not a clinically significant increase.

\section{Adherence}

Participants wore the CGM monitor a mean of $51.1429(\mathrm{SD}=20.68543)$ days with a range of 21 to 81, for this study wearing the monitor any part of the day was considered as a day for analysis. Participants wore the monitor a mean of 4.262 days a week. The previous JDRF study found improvement in Hbalc when the CGM monitor was worn 6 or more days a week (Beck et al., 2009a). In this study there was no correlation with duration of use of the CGM and the improvement in HbA1c (Pearson Correlation 0.334) $p=0.162$. There was no significant change in number of blood sugar tests (testing reported or actual) during the intervention. The study goal was to increase the average number of blood glucose tests to an average 3 tests per day. This goal was met at follow up visits two and three; however the mean number of test fell below 3 per at the final visit. The number of actual tests decreased close to baseline by the final visit. One concern was that the participants would test less with the monitor and rely on the readings of the CGM to dose insulin rather than on their home glucose monitor. A significant decrease in home blood sugar testing was not found to happen during this study.

\section{Hypoglycemia}

None of the participants reported having clinically significant hypoglycemia while wearing the monitor. Significant hypoglycemia is defined as requiring another person to help treat the hypoglycemia. This does not include symptomatic hypoglycemia that the participants were able to self-treat and correct on their own. Although, one participant reported report having 
two clinically significant hypoglycemia events during the study, the participant was not wearing the CGM monitor when he had the events. The CGM downloads reports showed the participants had blood sugars of $<70 \mathrm{mg} / \mathrm{dl}$ a mean of $0.5 \%(\mathrm{SD}=0.5030)$ of the total time the CGM was worn with a range from 0 to $1.9 \%$. None of the recorded time in hypoglycemia on the CGM monitor was report as being clinically significant by the participants. Previous studies showed less hypoglycemia in groups wearing CGM compared to the control groups without CGM therapy (Battelino et al., 2011; Beck et al., 2009b). Wearing the CGM in combination with improving glycemic control does not appear to be associated with self-reported clinically significant hypoglycemia. These findings are similar to those reported in previous studies. Nevertheless, participants with improved glycemic control need to be aware of increased risk of hypoglycemia and should monitor their blood glucose and symptoms very closely.

\section{Quality of life}

While there were no significant differences in quality of life among the six areas evaluated, two areas - parental impact and worry about diabetes - had overall higher scores than symptoms, treatment, activities and health. There was a trend in improvement of areas of symptoms, treatment, parental issues, worry, and health. The areas related to activities worsened from the baseline visit. While these trends were identified, none of the changes were statistically significant. The highest area reported was in worry about diabetes. These areas related to future issues and concerns such as marriage, children, education, body image and complication from diabetes. 


\section{Qualitative findings}

A majority of families (61.9\%) met on a regular basis to discuss the CGM monitor and the blood sugars. The families that met identified a number of blood glucose problem areas. They also were able to discover blood glucose problems that were not previously identified or known. All of the families had been instructed on use of the FADM model. The participants that did not wear the monitor on a regular basis did not have any consequences or penalties put in place for poor behavior. The two participants that manipulated the CGM data were the ones that the family did meet with their child to review the monitor on a regular basis. The families and participants found the monitor to be helpful in a number of areas. Those that were expected included more frequent dosing of insulin and detection of high and low blood sugars. The areas that were reported and not expected were improved attitude and improved parent interaction.

\section{Significance}

This study offers evidence that continuous glucose monitoring improves glycemic control in children, adolescents, and young adults with poorly controlled diabetes with a HbA1c $>9.0 \%$. This was a short-term 12-week intervention, so it is not known if there would be further improvement or regression of glycemic control with long-term continual use of CGM. The attrition rate for the study was high, and so future interventions should include focusing on improving retention rates in this difficult population. This intervention requires additional daily activities beyond what the participants had been doing and it may be more work than they are willing to do. It is possible for participants to manipulate the CGM monitor; close attention needs to be paid to participants whose family does not meet on a regular basis to monitor their child's care. Previous studies found improvement in glycemic control when the CGM monitor 
was worn 6 or more days a week. This study showed improvement in HbAlc when the mean number of days of CGM was about 4.2 days per week. Although there was improvement of HgA1c in this study, this improvement was not correlated with duration of CGM use. While there was one participant that reported significant hypoglycemia during the study, this happened when the participant was not wearing the CGM sensor. There was no clinically significant hypoglycemia reported when the participants were wearing the monitor.

\section{Practice recommendations}

Prior to this practice change project, CGM use was limited to request by patient or by recommendation for patients that had significant hypoglycemic events. The project findings showed that CGM can be successfully implemented in a clinical practice. We are now offering CGM monitoring to all patients who are not at goal of HbA1c and who have third party payer coverage for the system. Of the twenty-one participants that completed the study, four of the participants now have their own CGM monitors. There are a number of clinic patients that were not in the study that have been started on CGM monitors. While CGM monitoring is being implemented into our clinic, there is still a limitation with third party coverage, particularly Medicaid, Chips and West Virginia PEIA. That data from this practice change project will be used to work with these payers to expand coverage to this vulnerable population.

\section{Conclusions}

CGM with the FADM model was effective in improving glycemic control with children, adolescents and young adults with poorly controlled diabetes. There was a small but significant increase in weight during the intervention. There was no significant change in total daily dose of insulin reported, adherence with blood sugar testing or quality of life during the intervention. 
There was no clinically significant hypoglycemia reported during the CGM monitor use.

Qualitative data analysis revealed the participants and their families had improvement in attitude toward diabetes and improved parent child interactions. 


\section{References}

Ajzen, I. (1991). The theory of planned behavior. Organizational Behavior and Human Decision Processes, 50(2), 179-211.

Anderson, R. M., Funnell, M. M., \& Hernandez, C. A. (2005). Choosing and using theories in diabetes education research. The Diabetes Educator, 31(4), 513-520.

Battelino, T., Phillip, M., Bratina, N., Nimri, R., Oskarsson, P., \& Bolinder, J. (2011). Effect of continuous glucose monitoring on hypoglycemia in type 1 diabetes. Diabetes Care, 34(4), 795-800.

Beck, R. W., Buckingham, B., Miller, K., Wolpert, H., Xing, D., Block, J. M., ... \& Tamborlane, W. V. (2009a). Juvenile Diabetes Research Foundation Continuous Glucose Monitoring Study Group. Factors predictive of use and of benefit from continuous glucose monitoring in type 1 diabetes. Diabetes Care, 32(11), 1947-1953.

Beck, R. W., Hirsch, I. B., Laffel, L., Tamborlane, W. V., Bode, B. W., Buckingham, B., ... \& Xing, D. (2009b). The effect of continuous glucose monitoring in well-controlled type 1 diabetes. Diabetes Care, 32(8), 1378-1383.

Blevins, T. C., Bode, B. W., Garg, S. K., Grunberger, G., Hirsch, I. B., Jovanovič, L., ... \& Tamborlane, W. V. (2010). Statement by the American Association of Clinical Endocrinologists Consensus Panel on continuous glucose monitoring. Endocrine Practice, 16(5), 730-745.

Centers for Disease Control and Prevention. (2011). National diabetes fact sheet: national estimates and general information on diabetes and prediabetes in the United States, 2011. 
Atlanta, GA: US Department of Health and Human Services, Centers for Disease Control and Prevention, 3 .

Joubert, M., \& Reznik, Y. (2012). Personal continuous glucose monitoring (CGM) in diabetes management: Review of the literature and implementation for practical use. Diabetes Research and Clinical Practice, 96(3), 294-305.

Liese, A. D., D'Agostino Jr, R. B., Hamman, R. F., Kilgo, P. D., Lawrence, J. M., Liu, L. L., ... \& Williams, D. E. (2006). The burden of diabetes mellitus among US youth: prevalence estimates from the SEARCH for Diabetes in Youth Study. Pediatrics, 118(4), 1510-1518.

Methodology Checklist 1: Systematic Reviews and Meta-Analyses. (2012, February 27). Scottish Intercollegiate Guidelines Network. Retrieved from http://www.sign.ac.uk/guidelines/fulltext/50/checklist1.html

National Institute for Clinical Excellence (Great Britain). (2004). Type 1 diabetes : diagnosis and management of type 1 diabetes in children, young people and adults. London: NICE.

Polit, D. F. (2008). Nursing research: Generating and assessing evidence for nursing practice. Philadelphia: Lippincott Williams \& Wilkins.

Raccah, D., Sulmont, V., Reznik, Y., Guerci, B., Renard, E., Hanaire, H., ... \& Nicolino, M. (2009). Incremental Value of Continuous Glucose Monitoring When Starting Pump Therapy in Patients With Poorly Controlled Type 1 Diabetes The RealTrend study. Diabetes Care, 32(12), 2245-2250.

Schilling, L. S., Knafl, K. A., \& Grey, M. (2006). Changing patterns of self-management in youth with type I diabetes. Journal of Pediatric Nursing, 21(6), 412-424. 
Silverstein, J., Klingensmith, G., Copeland, K., Plotnick, L., Kaufman, F., Laffel, L., ... \& Clark, N. (2005). Care of children and adolescents with type 1 diabetes: A statement of the American Diabetes Association. Diabetes Care, 28(1), 186-212.

Skinner, T. C., Hoey, H., McGee, H. M., \& Skovlund, S. E. (2006). A short form of the Diabetes Quality of Life for Youth questionnaire: exploratory and confirmatory analysis in a sample of 2,077 young people with type 1 diabetes mellitus. Diabetologia, 49(4), 621628.

Solowiejczyk, J. (2004). The family approach to diabetes management: Theory into practice toward the development of a new paradigm. Diabetes Spectrum, 17(1), 31-36.

Sperling, M. (2002). Pediatric endocrinology. Philadelphia: Saunders.

Tamborlane, W. V., Beck, R. W., Bode, B. W., Buckingham, B., Chase, H. P., Clemons, R., ... Xing, D. (2008). Continuous glucose monitoring and intensive treatment of type 1 diabetes. The New England Journal of Medicine, 359(14), 1464-1476. doi:10.1056/NEJMoa0805017

Wilson, D. M., Xing, D., Beck, R. W., Block, J., Bode, B., Fox, L. A., ... \& Tamborlane, W. V. (2011). Juvenile Diabetes Research Foundation Continuous Glucose Monitoring Study Group. Hemoglobin A1c and mean glucose in patients with type 1 diabetes: analysis of data from the Juvenile Diabetes Research Foundation continuous glucose monitoring randomized trial. Diabetes Care, 34(3), 540-544.

Wojciechowski, P., Ryś, P., Lipowska, A., Gawęska, M., \& Małecki, M. T. (2011). Efficacy and safety comparison of continuous glucose monitoring and selfmonitoring of blood glucose in type 1 diabetes. Polskie Archiwum Medycyny Wewnętrznej, 121(10), 333-344. 


\title{
Evidence of Key Site Support (Appendix A)
}

\author{
WestVirginiaUniversity \\ ROBRRT C. BYRD HEALTH SCIENCES CENTER
}

Appendix Letter of Support

April 10, 2012

Kevin R. Lewis MSN, RN, PNP-BC, CDE

Clinical Assistant Professor

Department of Pediatric Endocrinology

WVU School of Medicine, Charleston Division

Dear Mr, Lewis:

WVu Department of Pediatrics is pleased to support your Capstone Propasal: Efficacy of Continuous Glucose Monitoring in Children and Young Adults with Poorly Controlled Type 1 Diabetes. Given the incidence type 1 diabetes at our facility, we would welcome the opportunity to assist you in this project.

Please let me know how the clinical staff and management staff can assist you in this very important project.

Sincerely,

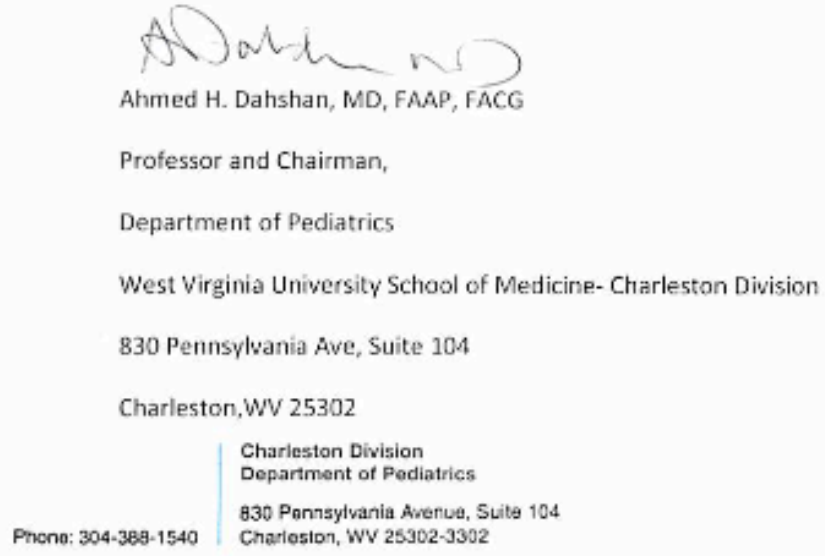


Continuous Glucose Monitoring Data Collection Tool (Appendix B)

Patient ID:

Age:

Gender: Male ___ Female

Pubertal Status: Pre __ Post

Other health conditions:

Age at diagnosis

Number of years with diabetes:

Lives with: Mother Father Grandparent Extended Family Other:

Baseline Visit Data:

HbA1c Level: $\%$

Reported number of blood sugar tests per day: Actual from meter:

Total Insulin Dose reported given per day units/kg/day

Quality of Life tool completed: 
Visit 2 Data (one month):

Reported number of blood sugar tests per day:

Actual from meter:

Total Insulin Dose reported given per day units/kg/day

Reports of Severe hypoglycemia requiring assistance: number of events:

Visit 3 Data (two months):

Reported number of blood sugar tests per day: Actual from meter:

Total Insulin Dose reported given per day units/kg/day

Reports of Severe hypoglycemia requiring assistance: number of events:

Final Visit Data (three months):

HbA1c Level: $\%$

Reported number of blood sugar tests per day: Actual from meter:

Total Insulin Dose reported given per day units/kg/day

Reports of Severe hypoglycemia requiring assistance: number of events:

Quality of Life tool completed: 
Qualitative data collection tool patients: (Appendix C)

Participant Name:

Visit:

Did you meet on a regular basis to discuss the diabetes regimen?

What did you discuss at these meetings?

Did you implement the consequences for non-adherence? If yes were they successful, if no, why not?

How do you think the CGM system is beneficial or not beneficial?

Are there any problems you are having with the system? 
Capstone Budget (Appendix D)

\section{BUDGET FOR CONDUCTING STUDY}

Effectiveness of Continuous Glucose Monitoring in Children and Adolescents

With Poorly Controlled Type 1 Diabetes

\section{PLEASE ITEMIZE IN DETAIL THE ESTIMATED COSTS TO CONDUCT THIS STUDY. \\ DIRECT COSTS \\ Medtronic \\ Requested}

Funds

Donated Costs

\section{PERSONNEL}

Consultants/Temporary

(Hourly rate $\mathrm{x} \#$ of hrs)

$\$$

Consultants/Temporary

(Hourly rate $\mathrm{x} \#$ of hrs)

$\$$

$\$$

Consultants/Temporary

(Hourly rate $\mathrm{x} \#$ of hrs)

$\$$

$\$$

Other Contractual Services

$\$$

$\$$

$\$$ 
Supplies

Item \#1 (Unit cost + tax) CGM Sensors $\$$

$\$ 36000$

$\$$

Item \#2 (Unit cost + tax)

$\$$

$\$$

Miscellaneous

Telephone Costs

$\$$

$\$$

Printing Costs (\# x cost per item)

$\$$

$\$$

Copier Costs

$\$$

$\$$

$\$$

$\$$

$\$$

$\$$

Postage/Fed. Ex

$\$$

$\$$

Software Costs

$\$$

$\$$

Slides for presentation

$\$$

$\$$

Other (list each item)

$\$$

$\$$

\section{Patient Care Costs}

Pharmacy/Drugs

$\$ \_1000$

$\$$

Laboratory

$\$ \quad 656$

$\$$

Lab \#1

$\$$

$\$$

Lab \#2

$\$$

$\$$

Patient Reimbursement

$\$ \quad 3200$ 
Travel

Travel Related to study conduct

$$
\$
$$

$\$$

Presentation Travel (Indicate set amount \$1500) \$ $\quad$ _ 1500

$\$$

TOTAL COSTS REQUESTED

$\$ \_6356$

TOTAL COSTS DONATED

\$_61980 


\section{Agreement for us of Quality of Life Tool (Appendix E)}

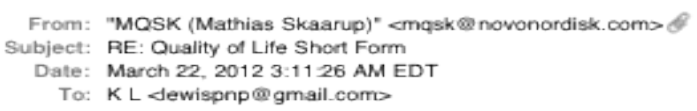

I want to follow up with you and make sure that you received the request for use of the Quality of Life Short Form for use in my study.

Thank you for your interest,

Kevin

Kevin Lewis 